\title{
ANALISIS KEANDALAN PADA STRUKTUR RANGKA BATANG MENGGUNAKAN SECOND ORDER RELIABILITY METHOD (SORM)
}

\author{
Adriyansyah \\ Email : adriyan_ubb@yahoo.com \\ Jurusan Teknik Sipil Fakultas Teknik Universitas Bangka Belitung \\ Kampus Terpadu UBB Balunijuk, Merawang, Kab. Bangka
}

\begin{abstract}
ABSTRAK
Untuk menghadapi dunia struktur konstruksi yang semaik modern dan permasalahan desain yang semakin kompleks, seorang ahli struktur dituntut untuk lebih rasional dalam menyelesaikan permasalahan. Ketidakpastian dalam geometri, sifat material, maupun pembebanan harus ditangani lebih rasional. Sehingga konsep desain yang semula menggunakan konsep deterministik sekarang beralih menggunakan konsep probabilistik. Salah satu metode probabilistik yang dapat digunakan yaitu Second Order Reliability Methods (SORM).

Second Order Reliability Methods (SORM) merupakan metode untuk menganalisis keandalan dengan menggunakan indeks keamanan $\beta$ dalam menentukan peluang kegagalan dari desain suatu struktur konstruksi banguanan. SORM menggunakan deret Taylor orde 2 dalam menyelesaikan fungsi kondisi batas.

Berdasarkan hasil analisis, profil baja yang memenuhi kriteria desain yaitu 2L 15x15x3 memiliki keandalan yang tinggi dan memiliki risiko kegagalan yang kecil dimana hasil analisis menunjukkan bahwa $p_{f}<0.1$.
\end{abstract}

Kata kunci : analisis risiko, keandalan, second order reliability method (SORM)

\section{PENDAHULUAN}

Untuk menghadapi perkembangan dunia struktur konstruksi yang semakin modern dan permasalahan desain yang semakin kompleks, seorang ahli struktur dituntut untuk lebih rasional dalam menyelesaikan permasalahan. Ketidakpastian dalam geometri, sifat material, maupun pembebanan harus ditangani lebih rasional. Sehingga konsep desain yang semula menggunakan konsep deterministik sekarang beralih menggunakan konsep probabilistik.
Konsep deterministik mendefinisikan keamanan struktur melalui faktor keamanan yang digabungkan dengan analisis tegangan elastis yaitu tegangan akibat beban lebih kecil atau sama dengan tegangan material yang dibagi faktor keamanan. Faktor keamanan didapat dari pengamatan eksperimental ataupun dari pengalaman praktis. Berbeda dengan konsep probabilistik yang menggunakan fungsi kondisi batas (limit state function) dalam bentuk fungsi matematika untuk menyelesaikan masalah desain pada struktur. 
Masalah keandalan struktur direpresentasikan sebagai persamaan kondisi batas dalam bentuk $g(X)=R(X)$ $S(X)$ dimana $R$ adalah resistensi dan $S$ adalah sistem pembebanan. Fungsi $g(X)$ merupakan batas antara daerah aman dan tidak aman dalam ruang parameter desain. Umumnya yang menjadi kondisi batas dalam desain struktur yaitu tegangan dan defleksi.

Semua parameter dalam analisis dan desain teknik memiliki derajat ketidakpastian yang mana parameter tersebut dipandang sebagai variabel acak. Sebagai contohnya jika beberapa sampel batang baja diberikan pembebanan sampai mengalami kegagalan maka tiap sampel tersebut akan mengalami kegagalan pada nilai beban yang berbeda. Untuk menangani ketidakpastian tersebut maka diguanakan konsep probabilistiks. Salah satu metode probabilistik yang dapat digunakan yaitu Second Order Reliability Methods (SORM).

Second Order Reliability Methods (SORM) merupakan metode untuk menganalisis keandalan dengan menggunakan indeks keamanan $\beta$ dalam menentukan peluang kegagalan dari desain suatu struktur konstruksi banguanan. Berbeda dengan First Order Reliability Methods (FORM) dalam menentukan indeks keandalan, SORM menggunakan deret Taylor orde 2. Untuk permasalahan limit state yang linear, FORM mempunyai kinerja yang baik dalam mengestimasi peluang kegagalan. Tetapi untuk permasalahan limit state nonlinear, metode FORM dapat memberikan hasil yang tidak masuk akal dan tidak akurat karena FORM hanya bekerja dengan satu titik jarak minimum. Untuk menyelesaikan masalah tersebut maka digunakan SORM.

Pada penelitian ini akan dilakukan analisis keandalan struktur rangka batang menggunakan SORM . Persyaratan desain untuk peluang kegagalan struktur rangka batang diasumsikan $P_{f}<0.1$

\section{LANDASAN TEORI}

\section{Keandalan Struktur}

Keandalan struktur (reliability) adalah peluang tidak gagal dari suatu struktur ketika menahan beban yang bekerja.

Keadaan batas menunjukkan batas aman antara resistensi dan beban dari struktur. Fungsi kondisi batas $\mathrm{g}(X)$ dan peluang kegagalan di definisikan sebagai berikut :

$$
\begin{aligned}
& g(X)=R(X)-S(X) \\
& P_{f}=P[g(X)<0]=\int \cdots \int_{g(X)<0} f_{X}\left(x_{1}, x_{2}, \ldots, x_{n}\right) d x_{1} d x_{2} \ldots d x_{n}
\end{aligned}
$$

dimana $P(\cdot)$ adalah fungsi peluang, $R$ adalah resistensi dan $S$ adalah pembebanan. $R(X)$ dan $S(X)$ adalah fungsi dari variabel acak resistensi dan variabel acak beban. Notasi $g(X)<0$ melambangkan daerah kegagalan, $g(X)=$ 0 melambangkan permukaan kegagalan atau kondisi batas, dan $g(X)>0$ melambangkan daerah aman.

Fungsi keadaan batas untuk masalah ini yaitu :

Batang tarik

$P_{f}=\sigma_{t_{-} i j i n}-\frac{P_{t i}}{A_{i}}=X_{1}-\frac{X_{2 i}}{A_{i}}<0$ 


\section{Batang tekan}

$P_{f}=\sigma_{\mathrm{c}_{-} i j i n}-\frac{P_{c i}}{A_{i}}=X_{3}-\frac{X_{4 i}}{A_{i}}<0$

dengan :

$X_{l}=\sigma_{t \_i j i n}=$ Tegangan tarik ijin

$X_{3}=\sigma_{c_{-} i j i n}=$ Tegangan tekan ijin

$X_{2 i}=P_{t i} \quad=$ Gaya aksial tarik batang ke $i$

$X_{4 i}=P_{c i} \quad=$ Gaya aksial tekan batang ke $i$

$A_{i} \quad=$ Luas Penampang batang ke $i$

\section{Second Order Reliability Method (SORM)}

Tahapan penyelesaiaan SORM sebagai berikut :

Matriks Hessian dari kondisi batas dalam ruang normal standar di titik desain :

$H=\left[\begin{array}{cc}\frac{\partial^{2} g}{\partial F_{t}^{2}} & \frac{\partial^{2} g}{\partial F_{t} \partial A} \\ \frac{\partial^{2} g}{\partial F_{t} \partial A} & \frac{\partial^{2} g}{\partial A^{2}}\end{array}\right]$

Panjang vektor dari hasil turunan transformasi kondisi batas

$$
\|G\|=\sqrt{\sum_{i=1}^{n}\left(\frac{\partial g}{\partial u_{i}}\right)^{2}}
$$

Arah cosinus dari tangent pada kondisi batas $g(x)=0$

$$
\alpha_{i}=-\frac{\frac{\partial g}{\partial u_{i}}}{\|G\|}
$$

Matriks orthogonal awal $\mathrm{T}_{0}$

$$
T_{0}=\left[\begin{array}{cccc}
1 & 0 & \cdots & 0 \\
0 & 1 & \cdots & 0 \\
\vdots & \vdots & \ddots & \vdots \\
\alpha_{1} & \alpha_{2} & \cdots & \alpha_{n}
\end{array}\right]
$$

$T_{0}=\left[\left\{t_{01}\right\},\left\{t_{02}\right\}, \ldots,\left\{t_{0 n}\right\}\right]^{t} \quad$ dimodifikasi menggunakan orthogonal Gram-Schmidt yaitu

$t_{k}=t_{0 k}-\sum_{i=k+1}^{n} \frac{t_{i} t_{0 k}^{t}}{t_{i} t_{i}^{t}} t_{i}$

dimana :

$t_{k}=$ vektor baris dari modifikasi matriks orthogonal $T_{0}=\left[\left\{t_{01}\right\},\left\{t_{02}\right\}, \ldots,\left\{t_{0 n}\right\}\right]^{t}$ $k$ = range dari $\mathrm{n}, \mathrm{n}-1, \mathrm{n}-2, \ldots, 2,1$.

Matriks $A$ :

$$
A=\left[a_{i j}\right]=\frac{\left(T H T^{t}\right)_{i j}}{\|G\|}, \quad i, j=1,2, \ldots, n-1
$$

Vektor $\beta$ :

$$
\beta=\frac{\ln \left(\frac{\mu_{R}}{\mu_{S}}\right)}{\sqrt{\delta_{R}^{2}+\delta_{S}^{2}}}
$$

Peluang kegagalan berdasarkan pada $\beta$ di estimasi menggunakan model Breitung's :

$$
p_{f S O R M}=\Phi(-\beta) \prod_{i=1}^{n-1}\left(1+\beta k_{i}\right)^{-\frac{t}{2}}
$$

Peluang Keandalan :

$$
p_{r}=1-p_{f S O R M}
$$




\section{METODE PENELITIAN}

Tahapan awal dalam penelitian ini adalah mencari gaya-gaya dalam yaitu gaya aksial akibat beban yang bekerja pada struktur rangka batang. Kemudian menetapkan profil baja yang akan digunakan dalam desain. Dari luas penampang profil yang digunakan dilakukan analisis risiko dan keandalan menggunakan SORM untuk mengetahui peluang kegagalan dan peluang keandalan struktur.

Struktur rangka batang yang digunakan dalam penelitian ini dapat dilihat pada Gambar

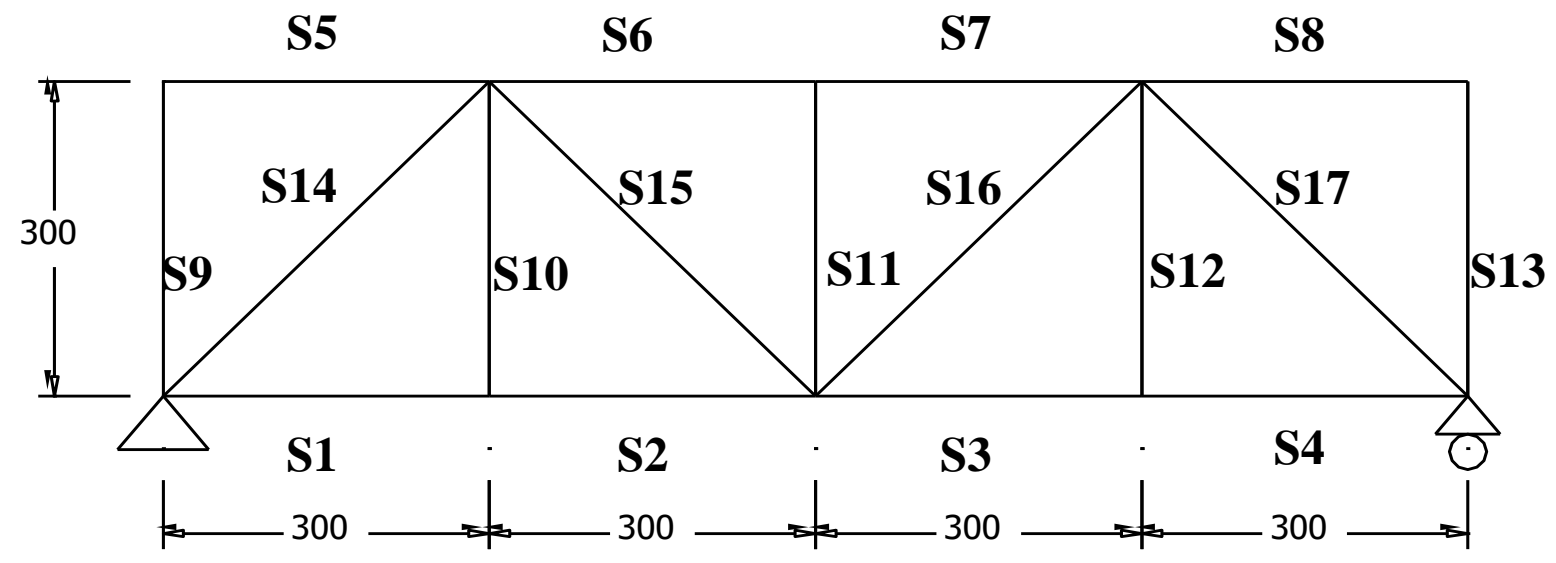

a. Struktur rangka batang dengan 17 elemen (satuan dalam $\mathrm{cm}$ )

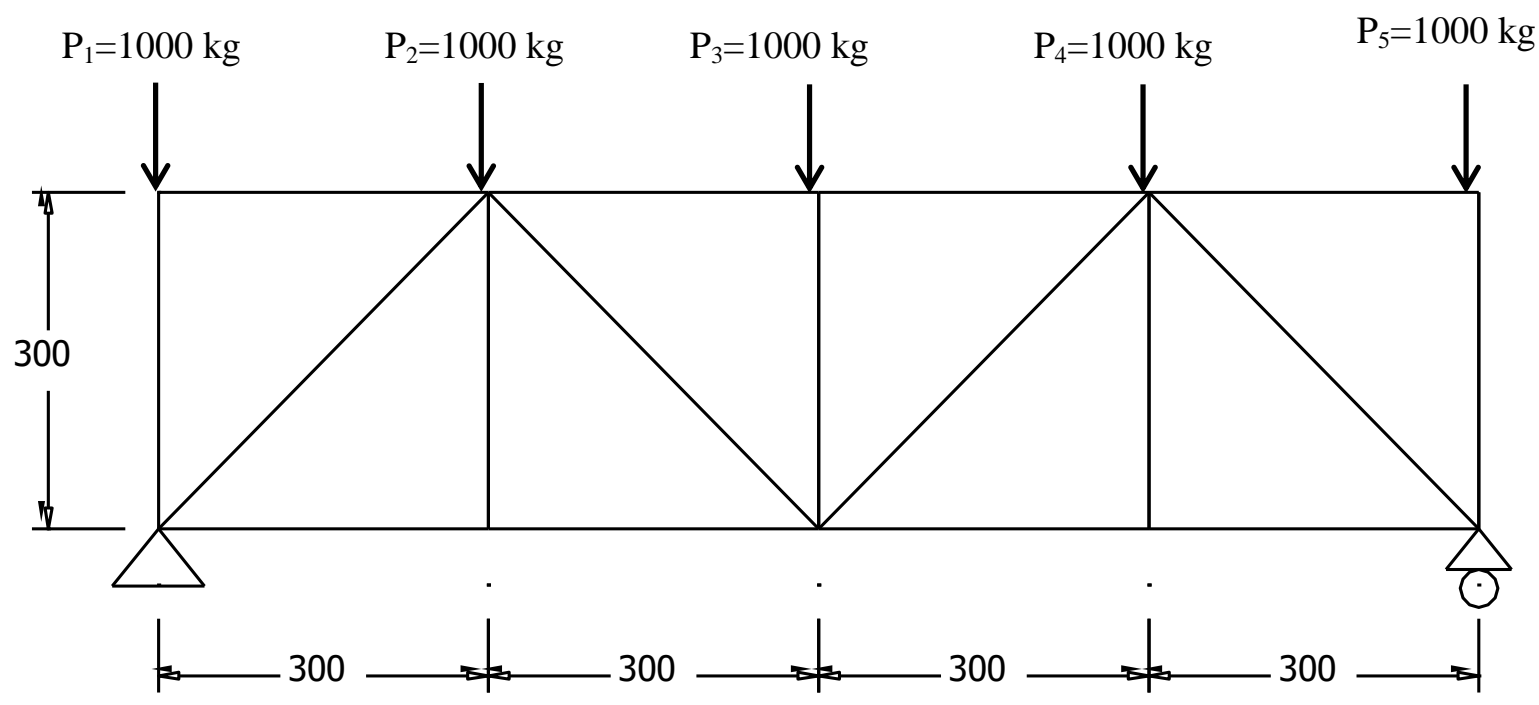

b. Pembebanan pada struktur rangka batang

Gambar 1. Struktur rangka batang yang ditinjau 


\section{HASIL DAN PEMBAHASAN}

Data yang digunakan pada penelitian ini adalah sebagai berikut :

Material baja BJ 37 dengan sifat mekanis baja :

Tegangan leleh $f_{y}=2400 \mathrm{~kg} / \mathrm{cm}^{2}$

Tegangan putus $f_{u}=3700 \mathrm{~kg} / \mathrm{cm}^{2}$

Profil baja yang digunakan $=$ Profil

$2 \mathrm{~L} 15 \times 15 \times 3$

Luas penampang $A=2 \times 0.62 \mathrm{~cm}^{2}=1.64$ $\mathrm{cm}^{2}$
Resistensi $R=\sigma_{i j i n}=1600 \mathrm{~kg} / \mathrm{cm}^{2}$ dengan asumsi rataan variabel acak resistensi $\mu_{R}=R$ dan koefisien variasi variabel acak resistensi $\delta_{R}=0.1$

Pembebanan $S=\frac{X_{2 i}}{A_{i}}$ untuk gaya aksial tarik dan $S=\frac{X_{4 i}}{A_{i}}$ untuk gaya aksial tekan dengan asumsi rataan variabel acak beban $\mu_{S}=S$ dan koefisien variabel acak beban $\delta_{S}=0.05$ Gaya aksial dari hasil analisis SAP 2000 adalah sebagai berikut :

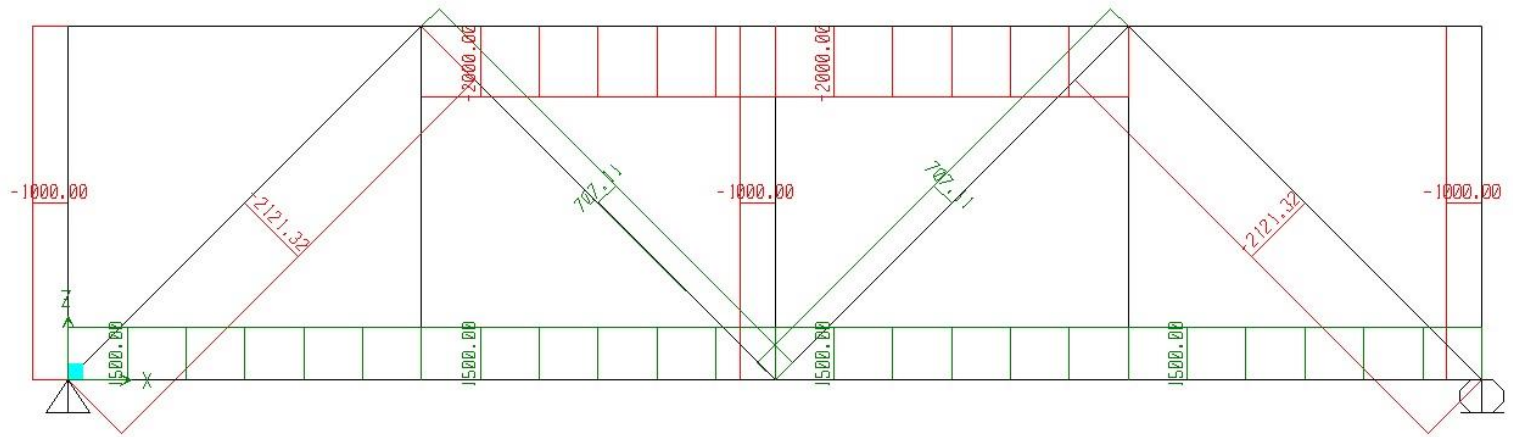

Gambar 2. Gaya aksial dari hasil output SAP 2000

Adapun hasil analisis yang didapat dari penelitian ini adalah sebagai berikut :

\begin{tabular}{|c|c|c|c|c|c|c|c|}
\hline $\begin{array}{c}\text { No. } \\
\text { Batang }\end{array}$ & Panjang & $\begin{array}{c}\text { Gaya- } \\
\text { gaya } \\
\text { Dalam } \\
(\mathbf{c m})\end{array}$ & Profil Baja & $\begin{array}{c}\text { Luas } \\
\text { Penampa } \\
\mathbf{n g} \\
\left(\mathbf{c m}^{2}\right)\end{array}$ & $\begin{array}{c}\text { Indeks } \\
\text { Keandalan } \\
\boldsymbol{\beta}\end{array}$ & $\begin{array}{c}\text { Peluang } \\
\text { Keandalan } \\
\mathbf{r}\end{array}$ & $\begin{array}{c}\text { Peluang } \\
\text { Kegagalan }\end{array}$ \\
\hline S1 & 300 & 1500 & $2 \mathrm{~L} 15 \times 15 \times 3$ & 1.64 & 5.0019 & 1 & 0 \\
\hline S2 & 300 & 1500 & $2 \mathrm{~L} 15 \times 15 \times 3$ & 1.64 & 5.0019 & 1 & 0 \\
\hline S3 & 300 & 1500 & $2 \mathrm{~L} 15 \times 15 \times 3$ & 1.64 & 5.0019 & 1 & 0 \\
\hline S4 & 300 & 1500 & $2 \mathrm{~L} 15 \times 15 \times 3$ & 1.64 & 5.0019 & 1 & 0 \\
\hline S5 & 300 & 0 & $2 \mathrm{~L} 15 \times 15 \times 3$ & 1.64 & 86.5836 & 1 & 0 \\
\hline S6 & 300 & -2000 & $2 \mathrm{~L} 15 \times 15 \times 3$ & 1.64 & 2.4288 & 0.9921 & 0.0079 \\
\hline
\end{tabular}




\begin{tabular}{|c|c|c|c|c|c|c|c|}
\hline $\begin{array}{c}\text { No. } \\
\text { Batang }\end{array}$ & $\begin{array}{c}\text { Panjang } \\
\text { (cm) }\end{array}$ & $\begin{array}{c}\text { Gaya- } \\
\text { gaya } \\
\text { Dalam } \\
\text { (kg) }\end{array}$ & Profil Baja & $\begin{array}{c}\text { Luas } \\
\text { Penampa } \\
\text { ng } \\
\left(\mathrm{cm}^{2}\right)\end{array}$ & $\begin{array}{c}\text { Indeks } \\
\text { Keandalan } \\
\beta\end{array}$ & $\begin{array}{c}\text { Peluang } \\
\text { Keandalan } \\
\mathbf{r}\end{array}$ & $\begin{array}{c}\text { Peluang } \\
\text { Kegagalan } \\
\text { Pf }\end{array}$ \\
\hline S7 & 300 & -2000 & $2 \mathrm{~L} 15 \times 15 \times 3$ & 1.64 & 2.4288 & 0.9921 & 0.0079 \\
\hline S8 & 300 & 0 & $2 \mathrm{~L} 15 \times 15 \times 3$ & 1.64 & 86.5836 & 1 & 0 \\
\hline S9 & 300 & -1000 & $2 \mathrm{~L} 15 \times 15 \times 3$ & 1.64 & 8.6285 & 1 & 0 \\
\hline S10 & 300 & 0 & $2 \mathrm{~L} 15 \times 15 \times 3$ & 1.64 & 86.5836 & 1 & 0 \\
\hline S11 & 300 & -1000 & $2 \mathrm{~L} 15 \times 15 \times 3$ & 1.64 & 8.6285 & 1 & 0 \\
\hline S12 & 300 & 0 & $2 \mathrm{~L} 15 \times 15 \times 3$ & 1.64 & 86.5836 & 1 & 0 \\
\hline S13 & 300 & -1000 & $2 \mathrm{~L} 15 \times 15 \times 3$ & 1.64 & 8.6285 & 1 & 0 \\
\hline S14 & 300 & -2121.32 & $2 \mathrm{~L} 15 \times 15 \times 3$ & 1.64 & 1.9021 & 0.9702 & 0.0298 \\
\hline S15 & 300 & 707.11 & $2 \mathrm{~L} 15 \times 15 \times 3$ & 1.64 & 11.7283 & 1 & 0 \\
\hline S16 & 300 & 707.11 & $2 \mathrm{~L} 15 \times 15 \times 3$ & 1.64 & 11.7283 & 1 & 0 \\
\hline S17 & 300 & -2121.32 & $2 \mathrm{~L} 15 \times 15 \times 3$ & 1.64 & 1.9021 & 0.9702 & 0.0298 \\
\hline
\end{tabular}

\section{KESIMPULAN}

Berdasarkan hasil analisis penelitian dapat diambil kesimpulan sebagai berikut :

1. Semakin besar indeks keandalan maka semakin kecil peluang kegagalan dan semakin besar keandalan struktur yang dirancang.

2. Profil baja siku yang digunakan yaitu 2L15x15x3 memiliki keandalan yang tinggi dan memiliki risiko kegagalan yang kecil dimana hasil analisis menunjukkan bahwa $p_{f}<0.1$.
(ANSI/AISC 360-10), American Institute Of Steel Construction, Chicago, Illinois, 22 June 2010. Gunawan, R., 1988, Tabel Profil Konstruksi Baja, Penerbit Kanisius.

Ranganathan, R., 1999, Structural Reliability Analysis and Design, Jaico Publishing House.

\section{DAFTAR PUSTAKA}

AISC, 2010, Specification for Structural Steel Buildings 